\section{THE WABASH CENTER}

JOURNAL on TEACHING

\title{
Theme-Centered Interaction (TCI) in Higher Education: A Didactic Approach for Sustainable and Living Learning
}

\author{
Sylke Meyerhuber, Helmut Reiser, and Matthias Scharer, editors \\ Cham, Switzerland: Springer, 2019 (xxii + 328 pages, ISBN 978-3-030-01047-8, \\ \$149.99)
}

Reviewed By
Jonghyun Kim
Garrett-Evangelical
Theological Seminary

$\mathrm{TCl}$ approach to building a better learning environment in higher education.

By offering diverse experiences of $\mathrm{TCl}$ through twenty contributors who work in various fields such as the social sciences and in religious contexts, Meyerhuber, Reiser, and Scharer explore the possibility of its application to a broader field. As described in chapter two, learning, for Cohn, is not assimilating the subject matter by attending to what a lecturer says.

We cannot exist as an individual learner in a classroom; we participate as members of a learning group that has its own different social and cultural background. Further, as Scharer notes, "a person becomes fully human by addressing the world with its many challenges, assignments, and knowledge" (73). Within this understanding of the learning environment, the subject matter cannot be determined by a lecturer alone. Instead, it should be created through "an interplay between people around the theme" (65).

Here, the lecturer is not just an expert who has special knowledge to give a right answer to their students, but is also a learner who learns "what their students need in order to learn the best they could" (ix). An individual learner is not passive but engages with other members of the class to participate in the learning process. Regarding this, M. E. Hess, in chapter eight, observes that Cohn's "Theme-Centered Interaction" process provides "a flexible yet structured, open yet bound, hospitable yet charged framework through which to shape reflective practice” (217).

In my opinion, the primary purpose of the lecture is to teach something to those who have no knowledge or skill regarding a certain topic. For example, teaching factual information focuses on delivering the content itself. In that case, critical feedback on the topic during the learning process might distract from the content, which must be delivered in a classroom. But as described in this book, forging an appropriate theme is the most important task, especially in higher education, in shaping a fully responsible human being with relation to others and the world. Disturbance in a group is an unavoidable factor. This book is valuable for all those who want to create a learning environment in order to start a meaningful conversation around a topic. 